Background: Interstitial lung disease associated with systemic sclerosis (ILD$\mathrm{SSc}$ ) is a frequent manifestation of the disease, impairing the quality of life and the prognosis of the disease. The efficacy of rituximab (RTX) in patients (pts) with ILD-SSC have been shown [1]. The "biosimilar" versions of RTX might reduce the cost of therapy and increase pts accessibility to this treatment option. The RTX biosimilar Acellbia (ACB), "BIOCAD", has received approval in Russian Federation in 2014 for all indications held by reference RTX

Objectives: to investigate the efficacy and safety of $A C B$ in naive to biological therapy pts with ILD-SSc during at least 12 month of follow-up.

Methods: Twenty pts were included in prospective observational study. The pts were aged 49,7 (s.d.14) years, 14 (70\%) were females, mean disease duration was $3,5 \pm 2,7$ years, with diffuse subset in $11(55 \%), 13(65 \%)$ were anti-topoisomerase positive, all pts has NSIP-pattern by HRCT. All pts were naive to ACB, received glucocorticoids in low doses, $10(50 \%)$ pts were previously treated with immunosuppressants and $4(20 \%)$ of them continued to take mycophenolate mofetil as a concomitant therapy. Pts received two courses of $A B C$ with the same scheme: $1 \mathrm{~g}$ repeated 1 week apart ( $4 \mathrm{~g} \mathrm{ACB}$ in total). An assessment of basic measurements was obtained at baseline (Point 0 ), before the second course

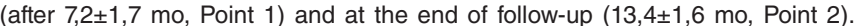
The results are presented in the form of mean values and standard deviations. Results: We observed a gradual improvement in the main parameters from Point 0 to Point 2 (table). Importantly, that at Point 1 there were no differences in most parameters, except for Rodnan skin score (mRSS) and the absolute number of B-lymphocytes (B-lymph), but at Point 2 there were significant differences between most basic outcome measures.

Table 1. Follow-up data of ACB treatment in ILD-SSC pts

\begin{tabular}{|c|c|c|c|c|c|}
\hline Parameters & $\begin{array}{l}\text { Point } 0 \\
(n=20)\end{array}$ & $\begin{array}{l}\text { Point } 1 \\
(n=20)\end{array}$ & $\begin{array}{l}\text { Point } 2 \\
(n=18) \#\end{array}$ & P 1-2 & P 1-3 \\
\hline mRSS & $12,75 \pm 11,1$ & $8,25 \pm 7,72$ & $6,16 \pm 5,65$ & 0,002 & 0,002 \\
\hline FVC $* \%$ pred & $89,1 \pm 18,2$ & $92,31 \pm 19,21$ & $98,26 \pm 16,13$ & NS & 0,0002 \\
\hline DLCO ${ }^{\star *}, \%$ pred & $56,67 \pm 15,7$ & $58,11 \pm 17,71$ & $61,86 \pm 17,16$ & NS & 0,019 \\
\hline SHAQ & $1,13 \pm 0,628$ & $0,98 \pm 0,678$ & $0,61 \pm 0,495$ & NS & 0,00001 \\
\hline $\lg G, g / l$ & $12,61 \pm 2,348$ & $11,5 \pm 1,61$ & $10,19 \pm 2,18$ & NS & 0,002 \\
\hline a-Topo-1, unit/ml & $109,68 \pm 86,92$ & $96,46 \pm 81,72$ & $72,46 \pm 69,46$ & NS & 0,004 \\
\hline B-lymph, absolute count & $0,329 \pm 0,34$ & $0,0016 \pm 0,003$ & $0,00189 \pm 0,003$ & 0,0004 & 0,001 \\
\hline Glucocorticoids, mg/day & $11,0 \pm 2,7$ & $10,75 \pm 2,0$ & $9,4 \pm 2,3$ & NS & 0,03 \\
\hline
\end{tabular}

${ }^{*} F V C$ - forced vital capacity \% predicted, ${ }^{\star}$ DLCO - diffusion capacity for carbon monoxide $\%$ predicted.\# Of the 20 patients who received the second course, 2 (10\%) dropped out the follow-up due to pregnancy (1) and lung cancer (1).

The frequency and spectrum of adverse events $(A E)$ corresponds to the known in the treatment of RTX, most AEs were classified as mild ones.There were 11 (55\%) of $A E$ in 9 (45\%) pts. Infections were observed in 7 (35\%) pts: 4 cases of acute respiratory tract infections, 2 cases of positivity in interferon-gamma release assayand one case each of otitis, cystitis, cholecystitis (9 AE in total). One pts developed low limb vein thrombosis and one - lung cancer. There were no infusion-related reactions.

Conclusion: The data from this prospective pilot study showed the effectiveness of the ACB in ILD-SSc. The clinical effect of ACB arises gradually and the baseline outcome measures reliably improve by the end of the first year. Our study have demonstrated a well-tolerated safety profile. We believe that ACB can be prescribed at SSc-ILD as a first-line drug and/or in the form of monotherapy. REFERENCES:

[1] Erre G.L., et.al. Efficacy, Safety, and Tolerability of Treatments for Systemic Sclerosis-Related Interstitial Lung Disease: A Systematic Review and Network Meta-Analysis. J.Clin.Med.2020,9,2560;doi:10.3390/jcm90825-60. Disclosure of Interests: None declared

DOI: 10.1136/annrheumdis-2021-eular.2338

\begin{tabular}{|l|l}
\hline POS0861 & EFFECTIVENESS AND SAFETY OF TOCILIZUMAB \\
& IN PATIENTS WITH SYSTEMIC SCLEROSIS: A \\
& PROPENSITY SCORE CONTROL MATCHED \\
& OBSERVATIONAL STUDY OF THE EUSTAR COHORT
\end{tabular}

S. Kuster ${ }^{1}$, S. Jordan ${ }^{1}$, M. D. Elhai2, U. Held ${ }^{3}$, K. Steigmiller ${ }^{3}$, C. Bruni ${ }^{4}$, F. lannone ${ }^{5}$, S. Vettori ${ }^{6}$, E. Siegert ${ }^{7}$, S. Rednic ${ }^{8}$, V. Codullo ${ }^{9}$, P. Airò ${ }^{10}$, Y. Braun-Moscovici ${ }^{11}$, N. Hunzelmann ${ }^{12}$, M. J. Salvador ${ }^{13}$, V. Riccieri ${ }^{14}$, A. M. Gheorghiu ${ }^{15}$, J. J. Alegre Sancho ${ }^{16}$, K. Romanowska-Prochnicka ${ }^{17}$ I. Castellvi ${ }^{18}$, I. Koetter ${ }^{19}$, M. E. Truchetet ${ }^{20}$, F. J. López-Longo ${ }^{21}$, P. Novikov ${ }^{22}$, A. Giollo ${ }^{23}$, Y. Shirai ${ }^{24}$, L. Belloli ${ }^{25}$, E. Zanatta ${ }^{26}$, E. Hachulla ${ }^{27}$, V. Smith ${ }^{28}$, C. Denton ${ }^{29}$, R. Ionescu ${ }^{30}$, T. Schmeiser ${ }^{31}$, J. H. W. Distler ${ }^{32}$, A. Gabrielli ${ }^{33}$ A. M. Hoffmann-Vold ${ }^{34}$, M. Kuwana ${ }^{24}$, Y. Allanore ${ }^{35}$, O. Distler ${ }^{2}$ on behalf of EUSTAR. ${ }^{1}$ University of Zurich, University Hospital Zurich, Department of Rheumatology, Zurich, Switzerland; ${ }^{1}$ University of Zurich, University Hospital Zurich, Department of Rheumatology, Zurich, Switzerland; ${ }^{3}$ University of Zurich, Department of Biostatistics at Epidemiology, Biostatistics and
Prevention Institute, Zurich, Switzerland; ${ }^{4}$ University of Florence, Division of Rheumatology, Department of Experimental and Clinical Medicine, Florence, Italy; ${ }^{5}$ GISEA, University Hospital of Bari, Bari, Italy; ${ }^{6}$ University of Campania 'Luigi Vanvitelli', Department of Precision Medicine, Naples, Italy; ${ }^{7}$ Charité Universitätsmedizin Berlin, Department of Rheumatology and Clinical Immunology, Berlin, Germany; ${ }^{8}$ University of Medicine \& Pharmacy "Iuliu Hatieganu"Cluj, Clinica Reumatologie, Cluj Napoca, Romania; ${ }^{9}$ University and IRCCS Policlinico S. Matteo Foundation, Division of Rheumatology, Pavia, Italy; ${ }^{10}$ University of Brecsia, ASST Spedali Civili of Brescia, Rheumatology and Clinical Immunology, Brescia, Italy; ${ }^{11}$ Rambam Health Care Campus, Rappaport Faculty of Medicine, Technion, B. Shine Rheumatology Unit, Hailfa Israel; ${ }^{12}$ Universtätsklinikum Köln, Universitätshautklinik Köln, Köln, Germany; ${ }^{13}$ University of Coimbra, University Hospitals, Department of Rheumatology, Coimbra, Portugal; ${ }^{14}$ Sapienza University, Department of Internal Medicine and Medical Specialties, Rome, Italy; ${ }^{15}$ Ion Cantacuzino Clinical Hospital, Department of Internal Medicine and Rheumatology Clinic, Bucharest, Romania; ${ }^{16}$ University of Valencia, University Hospital Dr. Peset, Department of Rheumatology, Valencia, Spain; ${ }^{17}$ Institute of Rheumatology, Department of Connective Tissue Disease, Warsaw, Switzerland; ${ }^{18}$ Hospital Universitari de La Santa Creu I Sant Pau, Department of Rheumatology, Barcelona, Spain; ${ }^{19}$ Asklepios Clinic Altona, Medical Department 4, Rheumatology, Immunology, Nephrology, Hamburg, Germany; ${ }^{20}$ National Reference Center for Systemic Autoimmune Rare Diseases, Hopital Pellegrin, Department of Rheumatology, Bordeaux, France; ${ }^{21}$ Hospital General Universitario Gregorio Marañón, Department of Rheumatology, Madrid, Spain; ${ }^{22}$ Sechenov First Moscow State Medical University, Clinic of Nephrology, Internal and Occupational Diseases, Moscow, Russian Federation; ${ }^{23}$ University of Verona, Rheumatology Section, Department of Medicine, Verona, Switzerland; ${ }^{24}$ Nippon Medical School Hospital, Allergy and Rheumatology, Tokyo, Japan; ${ }^{25}$ Niguarda Ca' Granda Hospital, Rheumatology Unit, Milano, Italy; ${ }^{26}$ University of Padova, Rheumatology Unit, Department of Clinical and Experimental Medicine, Padova, Italy; ${ }^{27}$ Referral Centre for Rare Systemic Auto-immune Diseases for North and North-West of France, University of Lille, Department of Internal Medicine, Claude Huriez Hospital, Lille, France; ${ }^{28}$ University of Ghent, Department of Rheumatology, Ghent, Belgium; ${ }^{29}$ Royal Free and University College London Medical School, Royal Free Campus, Centre for Rheumatology, London, United Kingdom; ${ }^{30}$ University of Medicine and Pharmacy, Department of Rheumatology - St. Maria Hospital, Carol Davila, Bucharest, Romania; ${ }^{31}$ Krankenhaus St. Josef, Innere Medizin und Rheumatologie, Wuppertal-Elberfeld, Germany; ${ }^{32}$ Universitätsklinikum Erlangen, Department of Internal Medicine 3, Erlangen, Germany; ${ }^{33}$ Istituto di Clinica Medica Generale, Università Politecnica delle Marche Polo Didattico, Ematologia ed Immunologia Clinica, Ancona, Italy; ${ }^{34}$ Rikshospitalet University Hospital, Department of Rheumatology, Oslo, Norway; ${ }^{35}$ Cochin Hospital, APHP, Paris Descartes University, Rheumatology A Department, Paris, France

Background: Tocilizumab (TCZ) showed trends for improving skin fibrosis and prevented progression of lung fibrosis in patients with systemic sclerosis (SSc) in placebo-controlled randomised clinical trials (RCTs). However, safety and effectiveness of TCZ beyond these selected and enriched clinical trial populations in $\mathrm{SSc}$ is still unknown.

Objectives: To assess safety and effectiveness of TCZ treatment compared to standard of care in SSc patients from the large, multicentre, observational, reallife EUSTAR network/database using propensity score matching.

Methods: SSc patients from the EUSTAR network/database, who fulfilled the ACR/EULAR 2013 classification criteria, with a baseline and a follow-up visit at $12 \pm 3$ months, receiving TCZ or standard of care (controls), were selected. The following variables were used for the propensity score matching (1:1): age at diagnosis, gender, disease subtype, baseline modified Rodnan skin score (mRSS), forced vital capacity (FVC), and diffusing capacity for carbon monoxide (DLCO), co-therapy with immunosuppressives, disease duration, and year of treatment. Primary endpoints were mRSS and FVC at $12 \pm 3$ months follow-up compared between the groups, using paired t-tests. Secondary endpoints were the percentage of progressive/regressive patients for skin and lung at $12 \pm 3$ months follow-up according to standard definitions $(1,2)$. Sensitivity analyses assessed pre-processing decisions (selection of most recent vs. random observation for control patients with multiple suitable time intervals), as well as the matching method (optimal vs. exact matching). Missing values were addressed with 100 -fold multiple imputation using chained equations. Safety data were analysed in all patients. The study including the statistical analysis plan was pre-registered at www.drks.de (DRKS-ID: DRKS00015537).

Results: We identified 93 SSc patients treated with TCZ and 2370 SSc patients with standard of care who fulfilled the inclusion criteria. Forty nine $(57.7 \%)$ of the TCZ treated patients were diffuse, eight patients were not classified, disease duration was (mean $\pm S D$ ) $6.35 \pm 5.40$ years, their baseline mRSS was $15.05 \pm 10.85$, and $76(81.7 \%)$ received immunosuppressive therapy in addition to TCZ.Through multiple imputation and propensity score matching, 100 imputed 
sets of 93 pairs of TCZ/controls were generated. Comparison between groups showed consistent effects of TCZ across all pre-defined primary and secondary endpoints: mRSS was lower in the TCZ group (mean difference $(95 \%$ confidence interval $(\mathrm{Cl}))-1.8$ (-4.79 to 1.19$), \mathrm{p}=0.24$, Figure $1 \mathrm{~A})$. Similarly, FVC \% predicted was higher in the TCZ group mean difference $(2.25,95 \% \mathrm{Cl}-4.57$ to 9.06$)$, $p=0.51$, Figure 1B). Considering secondary endpoints, the percentage of skin progressors as well as lung progressors at follow up was lower in the TCZ group (odds ratio OR 0.67 ( $95 \% \mathrm{Cl} 0.07$ to 6.41$), \mathrm{p}=0.74$ and OR $0.53(95 \% \mathrm{Cl} 0.16$ to $1.7) ; p=0.2$, respectively. Consistently, the percentage of regressors for skin (OR $1.6(95 \% \mathrm{Cl} 0.56$ to 4.54$), \mathrm{p}=0.38)$ and for lung (OR $1.74(95 \% \mathrm{Cl} 0.66$ to 4.58$)$, $\mathrm{p}=0.26$ ) was higher in TCZ. These results were robust regarding the sensitivity analyses. Safety analysis confirmed previously reported adverse event profiles.

Conclusion: In this large, observational, controlled, real-life EUSTAR study, effectiveness of TCZ did not reach statistical significance compared to standard of care treatment but showed consistent positive effects of TCZ on skin and lung fibrosis across all pre-defined primary and secondary endpoints confirming data from recent RCTs.

REFERENCES:

[1] Prediction of improvement in skin fibrosis in diffuse cutaneous systemic sclerosis: a EUSTAR analysis. Ann Rheum Dis 2016:1743-8.

[2] Progressive interstitial lung disease in patients with systemic sclerosis-associated interstitial lung disease in the EUSTAR database. Ann Rheum Dis 2021:219-227.

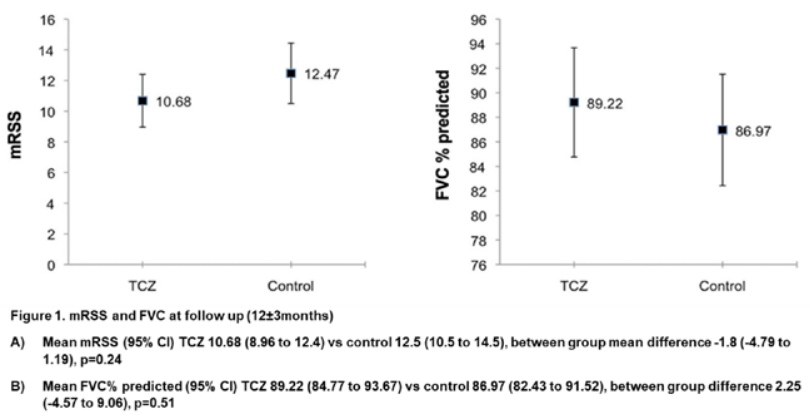

Disclosure of Interests: Simon Kuster: None declared, Suzana Jordan: None declared, Muriel Daniele Elhai: None declared, Ulrike Held: None declared, Klaus Steigmiller: None declared, Cosimo Bruni: None declared, Florenzo lannone: None declared, Serena Vettori: None declared, Elise Siegert: None declared, Simona Rednic: None declared, Veronica Codullo: None declared, Paolo Airò Consultant of: Dr. Airo' reports personal fees (consultancies) from Bristol Myers Squibb, Bohringer Ingelheim, non-financial support from CSL Behring, SOBI, Janssen, Roche, Sanofi, Pfizer, Yolanda Braun-Moscovici: None declared, Nicolas Hunzelmann: None declared, Maria Joao Salvador: None declared, Valeria Riccieri: None declared, Ana Maria Gheorghiu: None declared, Juan Jose Alegre Sancho: None declared, Katarzyna Romanowska-Prochnicka: None declared, Ivan Castellví: None declared, Ina Koetter: None declared, Marie-Elise Truchetet Consultant of: Marie-Elise Truchetet has had consultancy relationships and/or has received research funding from Boehringer Ingelheim, Genentech/ Roche, and Sanofi in the area of potential treatments of scleroderma and its complications., Grant/research support from: Marie-Elise Truchetet has had consultancy relationships and/or has received research funding from Boehringer Ingelheim, Genentech/Roche, and Sanofi in the area of potential treatments of scleroderma and its complications., Francisco J López-Longo: None declared, Pavel Novikov: None declared, Alessandro Giollo: None declared, Yuichiro Shirai: None declared, Laura Belloli: None declared, Elisabetta Zanatta: None declared, Eric Hachulla: None declared, Vanessa Smith: None declared, Christopher Denton: None declared, Ruxandra Ionescu: None declared, Tim Schmeiser: None declared, Jörg H.W. Distler: None declared, Armando Gabrielli: None declared, Anna-Maria Hoffmann-Vold Consultant of: AMHV has received research funding and/or consulting fees and/or other remuneration from Actelion, Boehringer Ingelheim, Roche, Bayer, Merck Sharp \& Dohme, ARXX, Lilly and Medscape, Grant/ research support from: $A M H V$ has received research funding and/or consulting fees and/or other remuneration from Actelion, Boehringer Ingelheim, Roche, Bayer, Merck Sharp \& Dohme, ARXX, Lilly and Medscape. Masataka Kuwana: None declared, Yannick Allanore: None declared, Oliver Distler Speakers bureau: Oliver Distler has/had consultancy relationship and/or has received research funding in the area of potential treatments for systemic sclerosis and its complications from (last three years): Abbvie, Acceleron Pharma, Amgen, AnaMar, Arxx Therapeutics, Baecon Discovery, Blade Therapeutics, Bayer, Boehringer Ingelheim, ChemomAb, Corbus Pharmaceuticals, CSL Behring, Galapagos NV, Glenmark Pharmaceuticals, GSK, Horizon (Curzion) Pharmaceuticals, Inventiva, iQvia, Italfarmaco, iQone, Kymera Therapeutics, Lilly, Medac, Medscape, Mitsubishi Tanabe Pharma, MSD, Novartis, Pfizer, Roche, Sanofi, Serodapharm,
Topadur, Target Bioscience and UCB. Patent issued "mir-29 for the treatment of systemic sclerosis" (US8247389, EP2331143)., Consultant of: Oliver Distler has/ had consultancy relationship and/or has received research funding in the area of potential treatments for systemic sclerosis and its complications from (last three years): Abbvie, Acceleron Pharma, Amgen, AnaMar, Arxx Therapeutics, Baecon Discovery, Blade Therapeutics, Bayer, Boehringer Ingelheim, ChemomAb, Corbus Pharmaceuticals, CSL Behring, Galapagos NV, Glenmark Pharmaceuticals, GSK, Horizon (Curzion) Pharmaceuticals, Inventiva, iQvia, Italfarmaco, iQone, Kymera Therapeutics, Lilly, Medac, Medscape, Mitsubishi Tanabe Pharma, MSD, Novartis, Pfizer, Roche, Sanofi, Serodapharm, Topadur, Target Bioscience and UCB. Patent issued "mir-29 for the treatment of systemic sclerosis" (US8247389, EP2331143)., Grant/research support from: The study was partially supported by a grant from Roche. Roche was not involved in analysis or interpretation of the results.

DOI: 10.1136/annrheumdis-2021-eular.2392

\section{POS0862 NAILFOLD CAPILLAROSCOPY IN UNDIFFERENTIATED AND MIXED CONNECTIVE TISSUE DISEASES}

C. Pizzorni ${ }^{1}$, G. Ferrari ${ }^{1}$, C. Schenone ${ }^{1}$, E. Gotelli ${ }^{1}$, S. Paolino ${ }^{1}$, A. Sulli ${ }^{1}$, G. Pacini ${ }^{1}$, E. Alessandri', V. Smith ${ }^{2}$, M. Cutolo' ${ }^{1}{ }^{1}$ Laboratory of Experimental Rheumatology and Academic Division of Clinical Rheumatology, Department of Internal Medicine, University of Genova, IRCCS San Martino Polyclinic Genoa, Italy; ${ }^{2}$ Department of Rheumatology - Department of Internal Medicine - Unit for Molecular Immunology and Inflammation, VIB Inflammation Research Center (IRC), Ghent University Hospital, Ghent, Belgium

Background: Microvascular damage is a frequent feature in connective tissue diseases (CTDs) and can be easily detected trough nailfold videocapillaroscopy (NVC) $(1,2)$. Mixed and Undifferentiated connective tissue diseases (MCTD and UCTD) do not show a specific and unique NVC pattern (3). However, a variety of microvascular abnormalities can occur in these two CTDs, both non-specific or specific for the scleroderma like-pattern (3-5).

Objectives: To retrospectively assess and compare nailfold microangiopathy observed by NVC in MCTD and stable UCTD versus primary Raynaud's phenomenon (PRP) (6). In addition, the aim was to correlate NVC findings with serum levels of autoantibodies (Abs) against extractable nuclear antigen (ENA) detected in UCTD.

Methods: Files of fourty-six MCTD patients (Kasukawa's criteria) (mean age $42.8 \pm 16$ SD years), fourty-seven UCTD patients (mean age $47.7 \pm 16.1$ SD years), fifty-one PRP (mean age $45.9 \pm 17.3$ SD years) were retrospectively evaluated in the study. Among UCTD and MCTD patients $95 \%$ of both showed Raynaud's phenomenon. Main NVC parameters (i.e. dilated capillaries, giant capillaries, microhemorrhages, abnormal shapes and number of capillaries) and related semiquantitative scale (score 0-3 for every parameter), were analyzed and compared between the two distinct CTD groups and PRP. Furthermore, ENA Abs (in particular, Ro/SSA, La/SSB, Scl70 and Jo1) were evaluated. The CTD patients were receiving different immunosuppressive treatments. Statistical analysis was performed by non-parametric tests.

Results: Among UCTD group, $36 \%$ of patients showed a normal NVC pattern, $53 \%$ had non-specific NVC abnormalities and $11 \%$ had a scleroderma like-pattern. The latter was significantly more frequent in MCTD than in UCTD $(p<0.001)$ in fact 22 out of $46(48 \%)$ MCTD patients presented a scleroderma-like pattern. On the other hand, normal pattern or non-specific NVC abnormalities were respectively found in $9 \%$ and $43 \%$ MCTD patients. Therefore, CTD patients showing giant capillaries, abnormal shapes (i.e. angiogenesis) and lower capillary density were significantly more affected by MCTD than UCTD $(p<0.001)$. Finally, the absolute number of capillaries was found significantly lower in MCTD versus UCTD patients (mean $7 \pm 1.7$ SD vs mean $9.2 \pm 1$ SD, respectively, $p<0.001)$. Not any statistical correlation was observed between NVC parameters and specific Abs ENA in UCTD. PRP showed a normal NVC pattern in $2 \%$ and non-specific capillary abnormalities in $98 \%$, (including dilated capillaries and microhemorrhages).

Conclusion: NVC features in UCTD patients seem very close to the pattern observed in PRP (mostly non-specific capillary abnormalities), conversely in MCTD the scleroderma-like pattern was found significantly prevalent together with a significant capillary number reduction. The transition from the scleroderma-like to the scleroderma pattern (mean systemic sclerosis) is matter of actual investigation.

\section{REFERENCES:}

[1] Cutolo M. et al. Best Pract Res Clin Rheumatol 2008; 22:1093-108.

[2] Sulli A, Ann Rheum Dis. 2008;67:885-7.

[3] Smith V. et al. Autoimmunity Reviews 2020; 19:102458.

[4] De Holanda Mafaldo DA, et al. Lupus. 2007; 16:254-8.

[5] Smith V, et al. Ann Rheum Dis 2010; 69: 1092-96.

[6] Antunes M, et al. RMD Open. 2019, 26;4.

Disclosure of Interests: None declared

DOI: 10.1136/annrheumdis-2021-eular.2562 